\title{
Mobile Web-Based Student Integrated Information System
}

\author{
Maria Cecilia G. Cantos, Lorena W. Rabago, and Bartlome T. Tanguilig
}

\begin{abstract}
This paper describes a conducive and structured information exchange environment for the students of the College of Computer Studies in Manuel S. Enverga University Foundation in Lucena City, Philippines. The system was developed to help the students check their academic result every end of the semester, make self-enlistment that would assist the students to manage their academic status that can be viewed in their mobile phones. This system would also help the dean to predict how many number of sections to be created for the next semester. The researchers applied Hill Climbing Algorithm search technique for the system particularly in creating self-enlistment and finding the best set of courses to the class schedule, and in projection of number of sections to be created for the next semester. Rapid Application Development (RAD) was utilized for the system development; PHP as the programming language, and MySQL as the database. The testing process of the system was done before deploying it to the internet. The process was done in different processors, operating systems and different mobile device platforms. The system's evaluation involved 67 respondents from the College of Computer Studies in Manuel S. Enverga University Foundation in Lucena City, Philippines. The researchers made use of ISO 9126 based Likert modified scale type of questionnaire that assess the system's acceptability in terms of functionality, reliability, usability, efficiency, maintainability and portability. Non-probability sampling method was used in selecting respondents under a purposive-sampling scheme. The results of the evaluation for the prototype yielded a general weighted mean of 4.44 that describes the respondents strongly agree that the developed system was acceptable
\end{abstract}

Index Terms-Hill climbing algorithm, integrated system, mobile web-based, student information system.

\section{INTRODUCTION}

Student Integrated Information System is now a facility which universities and colleges use to manage the records of their students. The convenience of accessing the educational resources online makes the programs ideal for working professionals and students alike. With the widespread employment of distance learning education program, even most conventional colleges and universities are now offering online education. Along with this program, certificate, associates and bachelor's degree, master's degree, and doctoral degree can be acquired through distance learning

Manuscript received September 10, 2014; revised May 23, 2015.

M. C. G. Cantos is with the Manuel S. Enverga University Foundation, Lucena City, Quezon Province, Philippines. She is also with the Information Technology in Technological Institute of the Philippines, Quezon City, Manila, Philippines (tel.: +63423734027, +639994556893; e-mail: mgcantos@gmail.com).

L. W. Rabago and B. T. Tanguilig are with the Information Technology in Technological Institute of the Philippines, Quezon City, Manila, Philippines. education. Thus, the main advantage is to be able to have a place for the students in the appropriate instructional environment, which is in an online application.

Student advising is an essential component of a successful academic experience. Academic advisors are exposed to a variety of opportunities, enhancements, problems, and choices as technology becomes more prevalent in university campuses [1]. Various universities and institutions around the world use automated advising systems. They are helpful and beneficial for both advisors and advisees in that they contribute to assisting in making better-informed decisions and improved services [2].

Mobile computing is a versatile and potentially strategic technology that improves information quality and accessibility, increases operational efficiency, and enhances management effectiveness [3]. This is because of its capability to enable users to remain connected while on the move. High end-users can opt for satellite-based networking which provides wireless connectivity anywhere in the world [4].

In today's fast-paced and technology-driven community, quality education with essential systems being used is a necessity. Hence, Manuel S. Enverga University Foundation, Lucena City, Philippines has already an existing online student information portal in which students can only view their grades that can be accessed only through intranet. With this, the researchers looked into the workability of developing a mobile web-based student integrated information system that would give students an easy and speedy access through internet technology and use of mobile phones to a range of handy and important information about their school activities, program curriculum, enlistment and grades.

\section{OBJECTIVES AND SCOPE OF THE SYSTEM}

\section{A. Objectives}

The main objective of this paper was to develop and evaluate a Mobile Web-Based Student Integrated Information System for the College of Computer Studies in Manuel S. Enverga University Foundation, Lucena City, Philippines that will be useful to the students to check academic results, manage profiles, view grades and manage self-enlistment that can be viewed in mobile phones.

The specific objectives of the study are the following:

1) To analyze the existing student information portal to determine the functional requirements and overall architecture as a basis in designing the specifications of the system;

2) To design and develop a web-based student integrated information system and can be viewed through mobile phones; and 
3) To evaluate the acceptability of the proposed mobile web-based system through gathering important feedback from target users based on ISO 9126 standard characteristics of the software quality attributes in terms of functionality, reliability, usability, efficiency, maintainability and portability.

\section{B. Significance of Developing the System}

Improvement is a word that entails responsibility and achievement. Responsibility does not stop in introducing, but requires continuous enhancement so that the environment where they belong becomes challenging. This paper serves as a development and improvement in the lives of the people concerned and a step-forward for the continuous growth of the university. Basically, it is because learning for everyone is not confined to a manual process, this innovation may even give a way to the global competitiveness of College of Computer Studies in Manuel S. Enverga University, Lucena City, Philippines. Competitiveness is not only the major concern, but this also introduce cutting of expenses without sacrificing the quality of services offered to the students. Finally, matters concerning students can be easily compared and problems that may arise can be given urgent answer.

\section{System's Features}

Fig. 1 shows the UML use case diagram of the system. This presents the functionalities of the system and the system's requirements from the user's perspective. The system has five actors: the administrator, the dean, registrar, faculty member, and student.

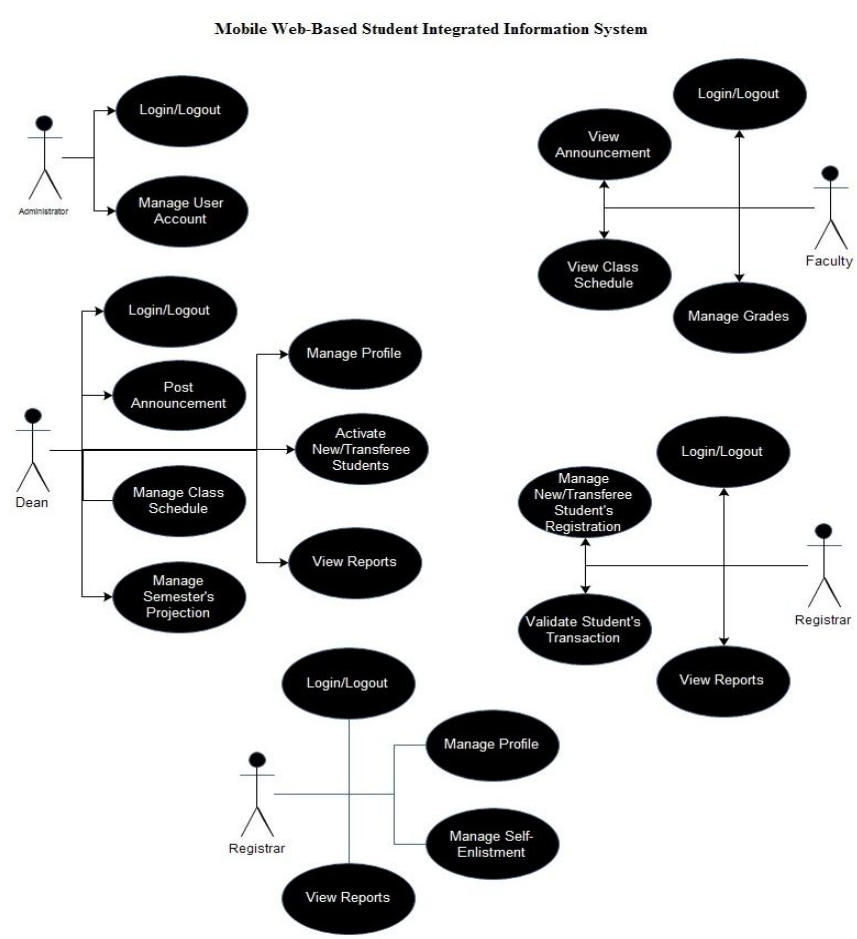

Fig. 1. UML use case of the system.

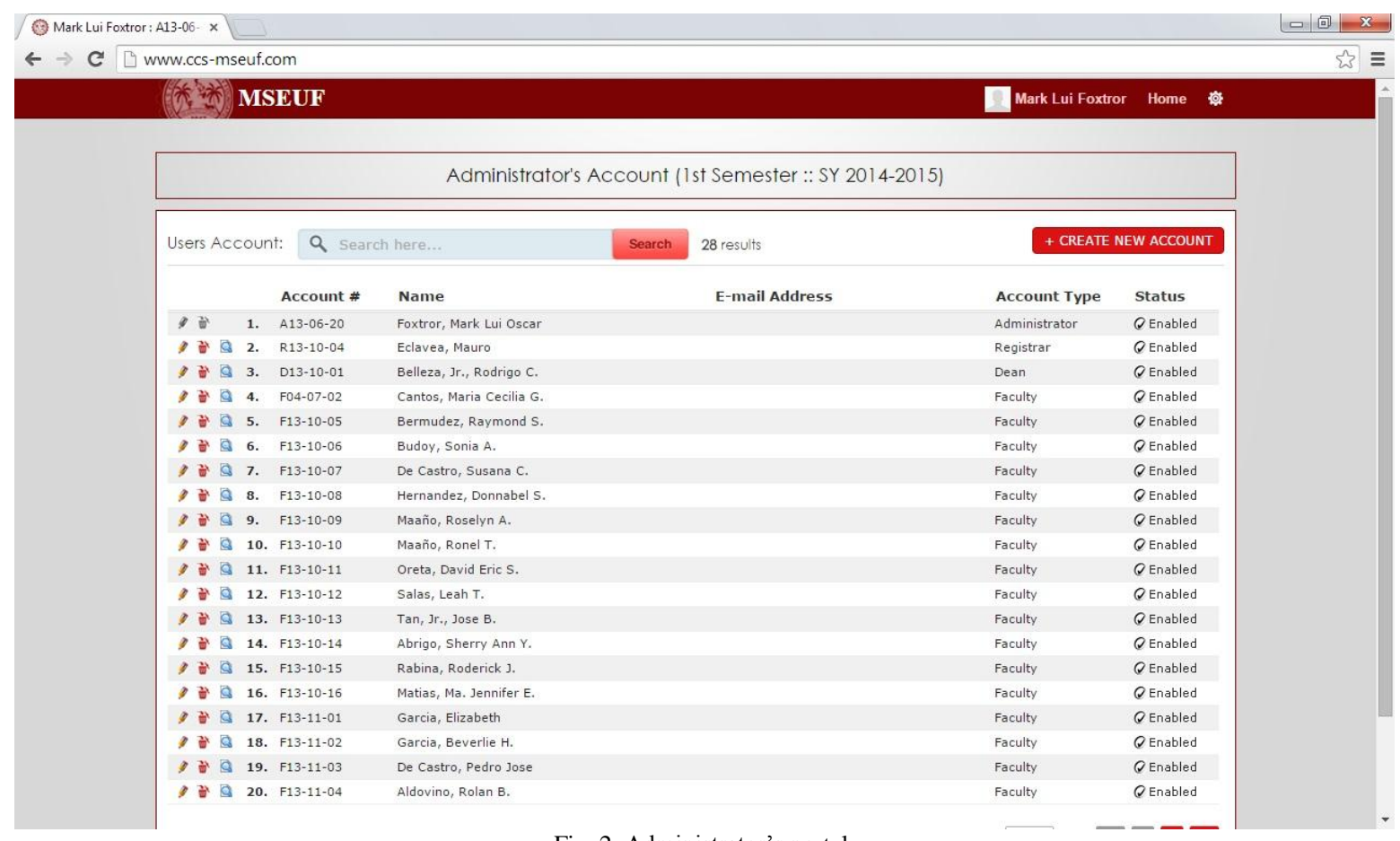

Fig. 2. Administrator's portal.

The administrator, as shown in Fig. 2, oversees the whole operation of the system. The administrator manages the user account of the would-be-users, where the administrator can add, edit, delete, and view user accounts as administrator, registrar, dean and faculty.

Fig. 3 illustrates the dean's portal in which the dean can manage profile (i.e. changing password, change pictures, etc.). He can also activate for the registered/enrolled student coming from the registrar if the student is a transferee/new student; post announcements that can be viewed by the students and faculty members; manage program curriculum; create faculty schedule according to the specialization and courses currently offering to the current academic year and semester. Moreover, the dean can prepare the number of sections for the next semester that will be based on the semester's projection menu based on the percentage of pre-requisite and non-pre-requisite courses; this menu will display the student's retention and will compare the number of sections created from the previous semester to the current semester. And, he can also view student's report, linked to the 
registrar's office, such as grades in a particular semester and evaluation/checklist sheet of the student.

Fig. 4 shown above is the registrar's page. The registrar is responsible for new /transferee student enrollment/registration. He can also use the system to validate student registration sent by the dean. He can also manage student's request such as: changing/adding/dropping courses of the student. He can also post the activities that are related to academic; activate current semester and current academic school year; manage students' records like viewing the grades of the students and the curriculum of the different courses offered by the college and view student information; and view the evaluation checklist of the students where he can monitor the status of the students' grades from the students' previously taken and currently enrolled courses.

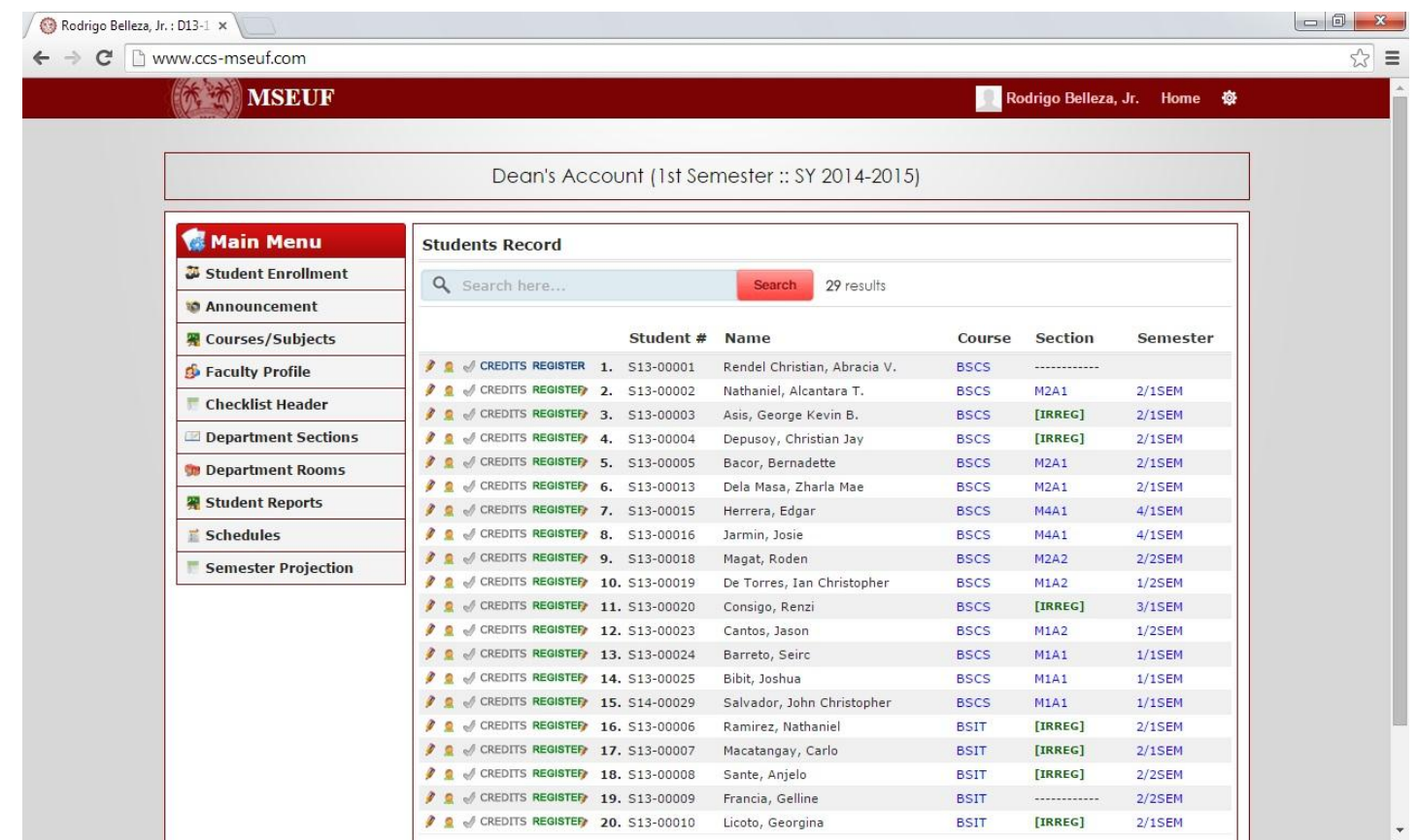

Fig. 3. Dean's portal.

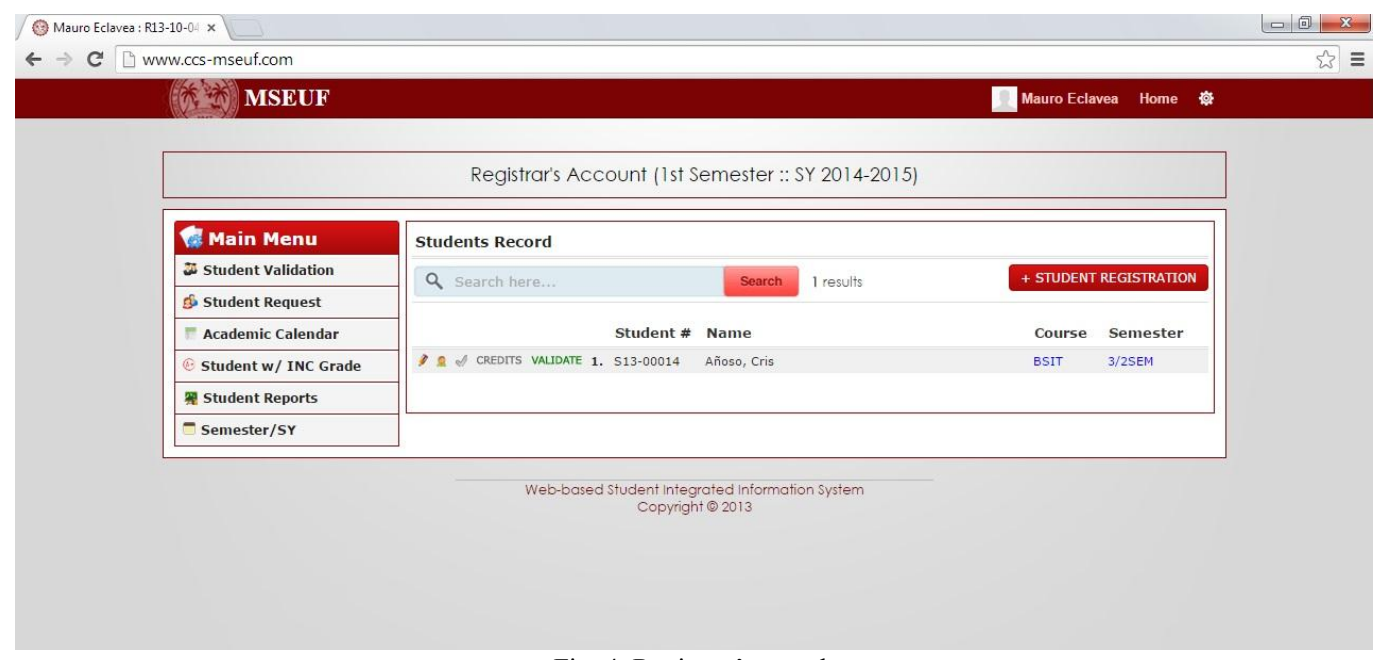

Fig. 4. Registrar's portal

The faculty account, as shown in Fig. 5, can also access the system where he/she can view announcements from the registrar or dean; view enrolled students with a corresponding class schedule; view class schedules plotted by the dean; and manage grades of the students.

Fig. 6 illustrates the students' account. The student is the main user of this system. By using the system, a student can manage profile (i.e. changing password, change pictures, etc.). $\mathrm{He} / \mathrm{she}$ can view announcements, class schedule, grades and program curriculum. Students can also monitor their evaluation/checklist for them to know which course will be taken for the next semester or what courses are taken already. The system will automatically determine the year level of the students according to their credited courses or courses taken. If a student is a regular student, the class schedule of a particular block section will be displayed automatically. However, if a student is an irregular student, the system should check first the following:

1) Pre-requisite or co-requisite check: if the course has any pre-requisite and co-requisite from the curriculum; and whether the student passed the requisite. If the student doesn't, he/she will not be able to take such course;

2) Course is not offered anymore check: whether the course is still open. If not, the student will not be able to add such course; and

3) Credit course check: if the course that will be taken is 
credited or not.

The students can also manage their own enlistment in which the students will see the courses offered that are aligned to their program curriculum. The students can also send request to the registrar for approval with the following cases: when student wants to add/drop a particular course/s.

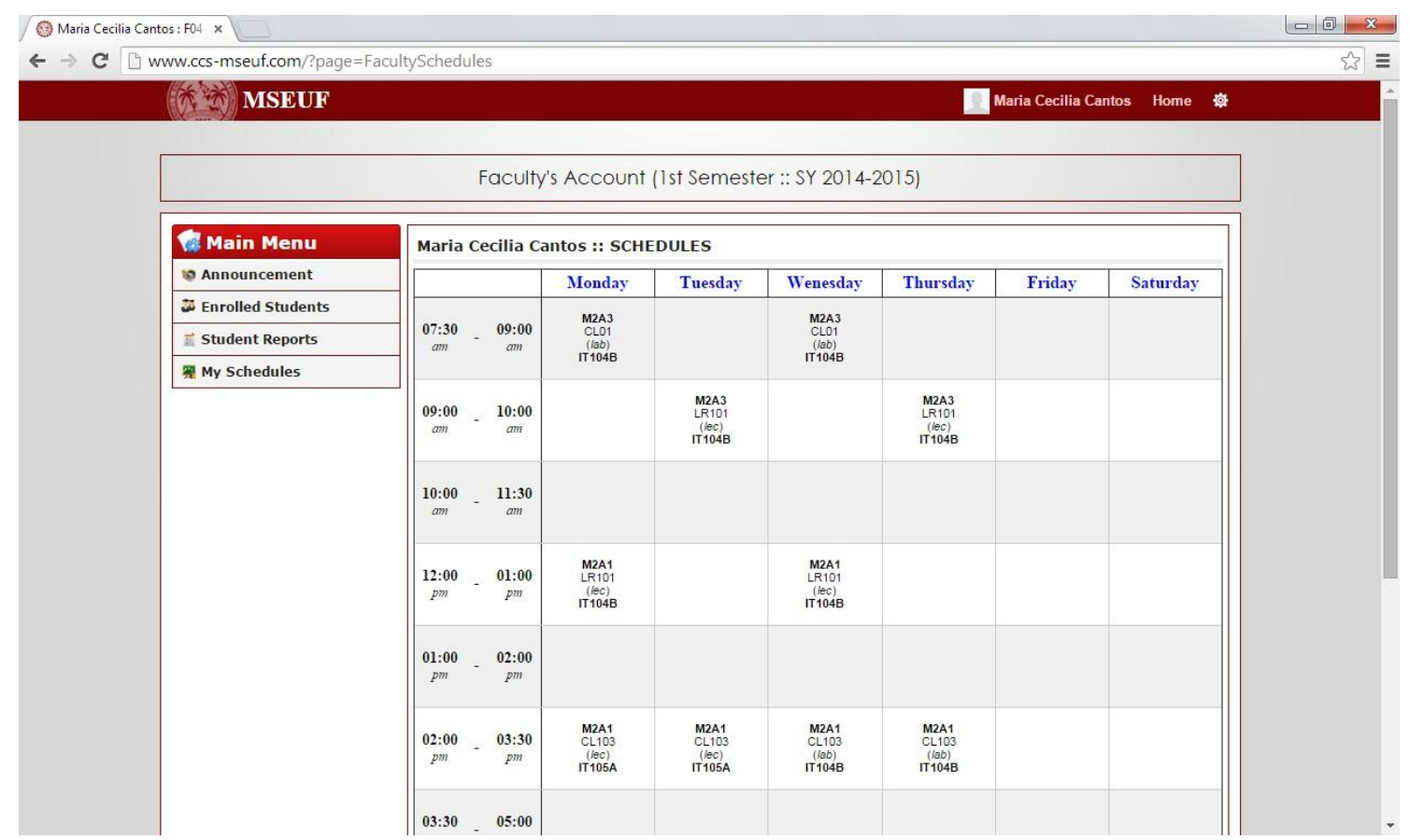

Fig. 5. Faculty’s portal.

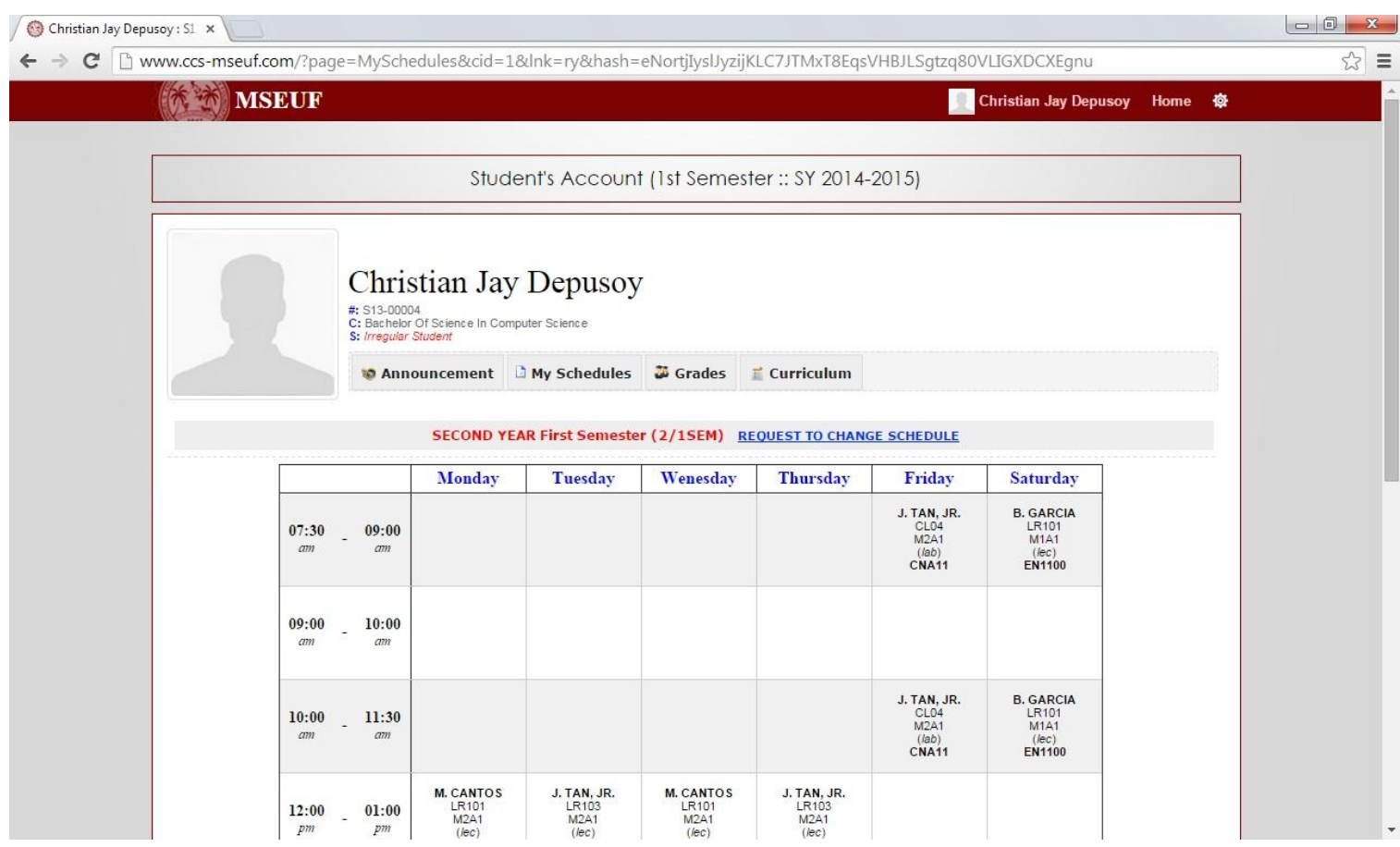

Fig. 6. Student's portal.

\section{RELATED WORKS}

As the present study being undertaken, the following literatures are showed and discussed briefly as they are related. These provide suggestions which are relevant and significant to the application of developing the system.

An expert system was used as an intelligent computer systems technology to support the academic advising process offers many advantages over the traditional student advising. The study proved that the developed a prototype for student advising using an expert system is successful and promising in which it assists the student needs in the field of Information Systems (IS) major in selecting their courses for each semester towards the academic degree [5].

Student advising is an important and time-consuming effort in academic life. The paper tried to solve a technology-based "last mile" problem by developing and evaluating a web-based decision support tool which is the Online Advisor that helps advisors and students make better use of an already present university student information system [6].

Good quality academic advising is subject to availability of experienced and committed personnel to undertake the task. 
The design and implementation of an intelligent Course Advisory Expert System (CAES) that uses a combination of rule based reasoning (RBR) and case based reasoning (CBR) was utilized to recommend courses that a student should register in a specific semester, by making recommendation based on the student's academic history. The evaluation of CAES yielded satisfactory performance in terms of credibility of its recommendations and usability [7].

An integration of inter-connectivity of information system (i3) in University of Sindh (UoS) was developed for sharing and exchanging all kinds of information mostly associated with students in different departments, and thus each department can easily and quickly find the status of student for required results. They have solved many problems frequently occurred in university information system [8].

Furthermore, the research paper of an Master of Science in Computer Science (MSCS) student developed and evaluated a mobile system providing user-centric information services for Norwegian University of Science and Technology (NTNU).According to the results, most of the participants strongly agreed to a mobile version of the time tables that are extremely useful [9].

Also, a WAP-Based Students Information System was developed to help the students and lecturers in campus to find and access information based on ad-hoc basic, which is of interest and relevant to students or lecturers; they only need a PDA or a mobile phone [10].

All of these related works have a common goal and that is ensuring that the students can access information at any time, at any location. A fast, accurate, fair and objective student integrated information system will definitely help students to check their academic standing and related courses information, view the own personal information, check for announcement, and even courses enlistment in a handy manner. With these existing applications in the market and with the works reviewed, the researchers drew the idea of proposing a mobile-based student integrated information system.

The problem of optimal system configuration for Web application servers wherein they formulated the problem of finding an optimal configuration for a given set of applications as a black-box optimization problem was studied. Then a Smart Hill-Climbing algorithm was proposed by using ideas of importance sampling and Latin Hypercube Sampling. Hence, the algorithm was efficient in both searching and random sampling. It consisted of estimating a local function, and then, Hill-Climbing in the steepest descent direction [11]. Likewise, hill climbing algorithm was only useful for relatively small graphs in a mapping technique. The results of the paper illustrated that hill climbing comes within a factor of two of optimum for the moderate size graphs considered. It was also stated that performance of hill climbing decreases with increasing graph size. They added that any state space search technique will probably suffer from large running times due to the size of the state space [12]. From the simulation results they had made decorrelating decision-feedback detector/detection (DDDF) join query that hill climbing algorithms was effective for delegating a query to a vertex where lower overall network traffic is incurred when the evaluation queries are retrieved in the distribution of data. Furthermore, they also stated that cost of performing the hill climbing algorithm was low compared to determining the global optimum location and delivered a large proportion of the delegation benefit [13].

Developing schedules of a particular student in traditional way is a long process that involves making many numbers of choices. It takes a long time and effort to accomplish. With Hill Climbing Algorithm, however, the process of class scheduling of a student can perform these processes faster and end up with an optimum solution.

\section{Hill Climbing Algorithm}

Hill climbing algorithm is simply a loop that continuously moves in the direction of increasing value, which is uphill. It stops when it reaches a "peak" where no neighbor has a higher value. The algorithm does not maintain a search tree, so the current node data structure need only record the state and its objective function value [14]. In this algorithm, only a local state is considered when making a decision which node is to expand next; when a node is entered all of its successor nodes have a heuristic function applied to them; the successor node with the most desirable result is chosen for traversal.

The Hill Climbing algorithm is an optimization problem that can usually also be modeled as a search problem; searching for the optimum solution from among the solution space. The hill climbing technique of search is as follows [15]:

1) Start with an initial solution, also called the starting point. Set current point as the starting point;

2) Make a move to a next solution, called the move operation; and

3) If the move is a good move, then set the new point as the current point and repeat 2). If the move is a bad move, terminate. The last current solution is the possible optimum solution.

\section{Hill Climbing Algorithm Implementation}

Since the major features of the system are creating self-enlistment and finding the best set of courses to the class schedule and the projection of number of sections to be created, Hill Climbing Algorithm was adopted as a search technique for the system. This technique helps the system's development foresee the process on how to produce a solution and output for a particular problem.

Fig. 7 depicts a complete graph of self-enlistment process of a student who finishes the program. The starting point of the process is when the student will register/enlist courses that correspond to his/her program curriculum. Each year and semester is referring to sets of courses that need to be completed before going to the next node or neighbor until it reaches the last node, the peak of the hill, which is to complete all courses according to the curriculum. Assume that $S$ node is a student; $I$ and $R$ nodes refer to a set of courses completed per semester and per year level; and $T$ node means that the student completed all the courses according to his/her program.

Let say, a student ( $S$ node) is a freshman student, first semester, and he/she will register courses. Definitely, the freshman student is a regular student, which is the $1.1 R$ node, therefore, he/she will register a block of section. Then, if the 
freshman student finishes the first semester and passed his/her registered set of courses, then he/she will automatically register the second semester's block section that is the $1.2 R$ node. Otherwise, the student will take a broken schedule only if he/she fails to complete the courses in the particular semester regardless of year level, the 1.11 node, which means, the student will become an irregular student and then it will continue to 1.2I node. Hence, the movement of the graph will vary through checking of the courses to the following instances: (a) pre-requisite / co-requisite; (b) course offering; and (c) passed / failed and automatically be an irregular student. The status in terms of year level of a transferee student may vary according to the credited courses aligned to the curriculum. From the $S$ node, the path can be in 1.11 node, or in $1.2 R$ node, or in 2.11 node, or in $2.2 R$ node depending on the credited courses; therefore, if the student will be any of these nodes, then, a broken schedule will be applied for the student. The student must reach the $T$ node that indicates all courses are completely done.

Moreover, the figure below presents the process on how the number of sections will be done that is also based on the hill climbing algorithm:

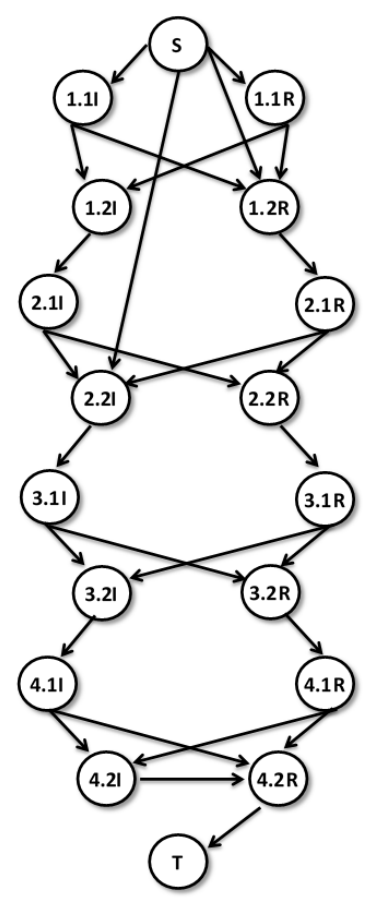

Fig. 7. Self-enlistment process.

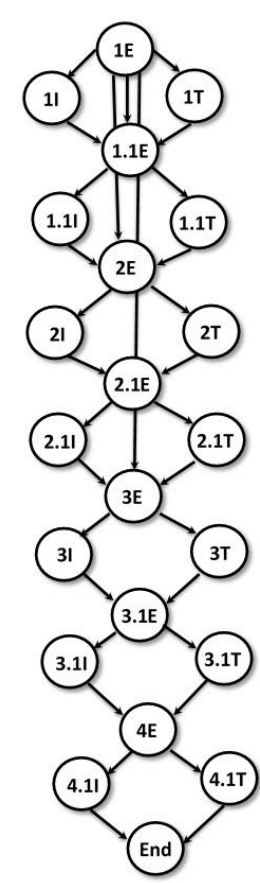

Fig. 8. Number of section projection process.
Prediction of the number of sections for the next semester is one of the considerations of the dean in creating teaching load/assignment of the faculty members. The one of the major features of the system is to project the number of sections per course that will be based on the previous semester according to the percentage for the pre-requisite and non-prerequisite courses that will be entered by the dean.

Fig. 8 shows the process on how hill climbing algorithm applied in the system. Nodes with $E$ refers to the enrollment, whether it is first semester or second semester; $I$ in the nodes, in the other hand, refers to number of sections to be created; and $T$, however, refers to number of faculty members. The $1 \mathrm{E}$ node denotes to the start of the first year, first semester of enrollment wherein if the university offers new programs, therefore, there will be no basis of comparison with regard to the number of sections created, but if there's an existing programs, there will be basis for the projection based on the previous semesters. From 1E node, it will be identified the number of sections, as directed to node 1I, that will be offered as per percentage ratio. Also, number of faculty members, $1 \mathrm{~T}$ node, needed will be identified based on $1 \mathrm{E}$ node. Furthermore, 1.1E node is the start of first year, second semester process and the basis of projection of preparation of number of section for this semester will be the number of students who have passed from $1 \mathrm{I}$ and $1 \mathrm{~T}$ nodes. The $1.1 \mathrm{I}$ node will identify again the number of sections to be offered as per the percentage ratio of $1.1 \mathrm{E}$ node; while $1.1 \mathrm{~T}$ node identifies the number of faculty members needed based on 1.1E node. Then, $2 \mathrm{E}$ node is the start of second year, first semester process and it will be based whether the students passed from the nodes of 1.1I and 1.1T. As the nodes of the graph traverse from one node to another, the process is repeated if the student passed the courses from previous semester in which it will be based on the previous number of sections created.

\section{Methodology}

Rapid Application Development (RAD) was used as the system development method. The proponent utilized Rapid Application Development approach in order to ensure the proponent that the system is really the users' need. Rapid Application Development (RAD) is a development lifecycle designed to give much faster development and higher-quality results than those achieved with the traditional lifecycle. It is designed to take the maximum advantage of powerful development software.

RAD compresses the step-by-step development of conventional methods into an iterative process. The RAD approach thus includes developing and refining the data models, process models, and prototype in parallel using an iterative process. User requirements are refined, a solution is designed, solution is prototyped, the prototype is reviewed, user input is provided, and the process begins again.

\section{Models, Technologies, Tools, and Techniques Used}

The following are the models, technologies, tools and techniques that the proponent used in the construction of the mobile web-based system.

The researchers used Unified Modeling Language (UML) in the illustration of the system to help them visualize the functions, flow and the components that will compose the system. These diagrams were used to illustrate the overview and functional requirements of the system.

PHP or Hypertext Preprocessor, a widely-used general-purpose scripting language especially suited for Web development that could be embedded into HTML [16], was utilized to develop a dynamic and functional web-based system to support and serve the mobile web-based system. Meanwhile, MySQL was used as the database.

In developing the system, Adobe Dreamweaver was the Integrated Environment Development (IDE) of the system which is very effective when developing using PHP and MySQL. Furthermore, Adobe Photoshop CS4 for designing 
the interface of the web-based part of the proposed system and for editing the images and MySQL for the database management system. Also, the fact-finding techniques were used in the data gathering.

\section{TESTING}

The system's testing process was done before uploading the system to the internet. The process was done in different processors, operating systems and different mobile device platforms.

The system was tested using a Dell Inspiron 640mlaptop in Windows 8 pro operating system with Intel Core $2 \mathrm{CPU}$ and an Acer Aspire V3-471G laptop with Intel Core i7-3610QMprocessor with Linux operating system. Moreover, the system was tested using Samsung Galaxy Tab P1000 with $2.3 \mathrm{x}$ version of android operating system and Apple Ipad4 with IOS7 operating system. Testing started by checking the compatibility to the platform and hardware that will be utilized in using the system.

Testing the system to different processor, operating system and different mobile platforms were performed. In terms of the compatibility to different operating systems, the system were functionally operated. However, in different platforms and sizes of mobile device, the resolutions of the mobile phones were the problems encountered that affects the interface of the system.

\section{RESULTS}

\section{A. Evaluation}

The evaluation of the system involved 67 respondents composed of dean, registrar, faculty members, and students of the College of Computer Studies in Manuel S. Enverga University Foundation in Lucena City, Philippines. The proponent used ISO 9126 based Likert modified scale type of questionnaire. The evaluation assess the system acceptability in terms of functionality, reliability, usability, efficiency, maintainability and portability. The researchers made use of non-probability sampling method in selecting respondents under a purposive-sampling scheme. A non-probability sampling method is a method in which not all members of the population have equal chances of being selected as respondent. The utilization of the purposive-sampling scheme facilitated the prompt tallying of evaluation sheet with consideration to the period of the study.

The "functionality" criterion measured the system's attribute in terms of suitability, accurateness, interoperability, compliance and security. "Reliability" is evaluated by maturity, fault tolerance and recoverability yielded by the system. "Usability" refers to the user's understandability, learnability, operability and attractiveness of the system. "Efficiency," on the other hand, depends on the resource utilization and time behavior. "Maintainability" is assessed by analyzability, changeability, stability and testability of the system. Lastly, "portability" refers to the adaptability, installability, conformance and replaceability of the system.

Table I shows the equivalent rating of the options given in the questionnaire for the respondents.

\section{B. Findings}

Table II shows the result of evaluation on the functionality, reliability, usability, efficiency, maintainability and portability of the system. The respondents strongly agree as presented by the result that the system operates with minimal human intervention as to answer the mobile web-based of the system, run in real time, communicate wirelessly, generate student's schedule automatically and predict number of sections to be created by the dean for the next semester. The functionality is highest ranked by the respondents. Reliability depicts the capability of the system to handle errors, runs smoothly, recovery from failure, operates accurately and the notification on an occurrence of error. The usability describes the system as user friendly, the providence of delivering comfort and convenience and if the system is manageable. The system as being efficient was strongly agreed by the respondents. The result shows the system's efficiency in terms of the process, response, accuracy, recording and displaying. The description also proves the rapid and instant response of the system. Furthermore, the result generated pronounces the capacity of the system to adhere on the objectives of the study. The result in maintainability illustrates that the system is maintainable in terms of detection of error, testability, adaptation to changes, modification of faults and viability. The portability results prove that the respondents agree on the capability of the system in terms of meeting the portability standard, design conformity, easy deployment and the co-existence of the software and hardware of the system.

TABLE I: LICKERT MODIFIED SCALE AND THE EVALUATION RESPONSE EQUIVALENT PER WEIGHTED MEAN

\begin{tabular}{ccc}
\hline \hline Numerical Rating & Arithmetic Mean Ranges & Equivalent \\
\hline \hline 5 & $4.21-5.00$ & Strongly Agree \\
4 & $3.41-4.20$ & Agree \\
3 & $2.61-3.40$ & Fair \\
2 & $1.81-2.60$ & Disagree \\
1 & $1.00-1.80$ & Strongly Disagree \\
\hline \hline
\end{tabular}

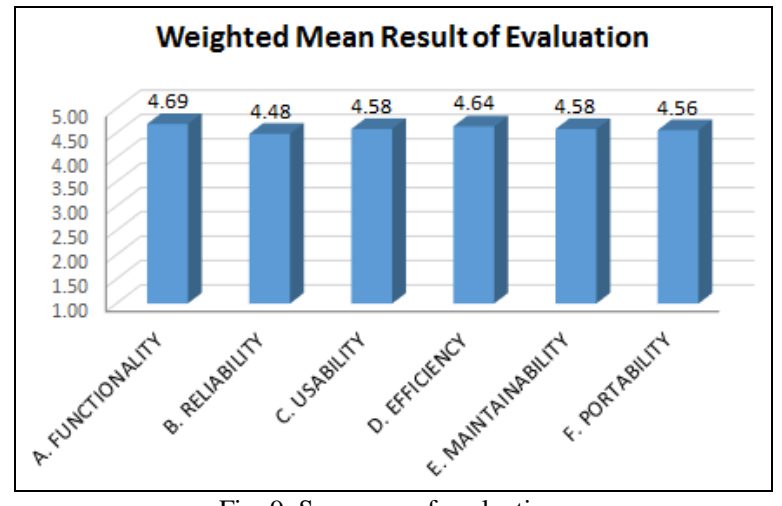

Fig. 9. Summary of evaluation.

The results of the evaluation yielded a general weighted mean of 4.59 that describes that the respondents strongly agree that the developed system is acceptable. Specifically, the system's rating criteria is as follows: "Functionality" 4.69, "Reliability" 4.48, "Usability" 4.58, "Efficiency" 4.64, "Maintainability" 4.58 and "Portability" 4.56. Fig. 9 illustrates the graphical representation of the results of the evaluation. The weighted mean described that the respondents 
strongly agree that the system is functional, reliable, efficient, usable, maintainable and portable.

The respondents strongly agreed that the acceptability factor of the system's functionality, reliability, efficiency, usability, maintainability and portability are significant. Some of the comments from the respondents are as follows:

1) The system is reliable, usable and efficient but suggests to include creation of teaching assignment for the late enrollees.

2) The system is reliable but could have included training for the clerk without computer literacy.

The respondents specifically the viewing of schedule of students that is generated automatically and the projection of number of sections for the next semester emphasize the potentials of the system in terms of functionality, reliability, usability, efficiency, maintainability, and portability.

TABLE II: ACCEPTABILITY OF THE SYSTEM

\begin{tabular}{|c|c|c|}
\hline System Acceptability Criteria & Weighted Mean & Equivalent \\
\hline \multicolumn{3}{|l|}{ A. Functionality } \\
\hline 1) The system can record information made by the user & 4.81 & Strongly Agree \\
\hline 2) The system has the ability to retrieve information & 4.81 & Strongly Agree \\
\hline 3) The system has the ability to register the student based on the step by step procedure of pre-enrollment & 4.69 & Strongly Agree \\
\hline 4) The system has the ability to generate student's schedule automatically & 4.61 & Strongly Agree \\
\hline $\begin{array}{l}\text { 5) The system has the ability to predict next semester's projection on number of sections, lec/lab rooms, } \\
\text { schedule of faculty per section, and comparison with the previous semester }\end{array}$ & 4.52 & Strongly Agree \\
\hline \multicolumn{3}{|l|}{ B. Reliability } \\
\hline 1) The system is capable of handling errors & 4.55 & Strongly Agree \\
\hline 2) The system is free from bugs and runs smoothly without interruption & 4.57 & Strongly Agree \\
\hline 3) The system can recover from failure and can resume operations & 4.43 & Strongly Agree \\
\hline 4) The system can still records information even error occurs & 4.43 & Strongly Agree \\
\hline 5) The software can recover even after failure & 4.43 & Strongly Agree \\
\hline \multicolumn{3}{|l|}{ C. Usability } \\
\hline 1) The system is user-friendly & 4.70 & Strongly Agree \\
\hline 2) Information are organized and well presented & 4.66 & Strongly Agree \\
\hline 3) Navigation on the different modules is easy & 4.52 & Strongly Agree \\
\hline 4) Features of the system can be easily determined by the users & 4.57 & Strongly Agree \\
\hline 5) The system can be used even if the users don't have technical experience & 4.46 & Strongly Agree \\
\hline \multicolumn{3}{|l|}{ D. Efficiency } \\
\hline 1) The system responds instantly & 4.55 & Strongly Agree \\
\hline 2) The system processes data quickly & 4.73 & Strongly Agree \\
\hline 3) The system can generate report quickly & 4.58 & Strongly Agree \\
\hline 4) The system instantly responds to command of the user & 4.69 & Strongly Agree \\
\hline 5) The system filter out precise information based on criteria & 4.63 & Strongly Agree \\
\hline \multicolumn{3}{|l|}{ E. Maintainability } \\
\hline 1) Errors can be easily detected by the system & 4.54 & Strongly Agree \\
\hline 2) The application can be easily modified & 4.60 & Strongly Agree \\
\hline 3) The application can continue functioning if changes are made & 4.45 & Strongly Agree \\
\hline 4) The application can be tested easily & 4.72 & Strongly Agree \\
\hline 5) It has an availability of system support & 4.61 & Strongly Agree \\
\hline \multicolumn{3}{|l|}{ F. Portability } \\
\hline 1) The software can be moved to other environments & 4.57 & Strongly Agree \\
\hline 2) The software can be deployed easily & 4.54 & Strongly Agree \\
\hline 3) The software complies with portability standards & 4.55 & Strongly Agree \\
\hline 4) The software can easily replace other software & 4.49 & Strongly Agree \\
\hline 5) The software can be deployed on other operating system & 4.64 & Strongly Agree \\
\hline
\end{tabular}

\section{CONCLUSION}

The development of the system was managed carefully to come up with the desired output. The comments given by the respondents comply with the result of the evaluation which corresponds that the system has met its objectives. Taking 
into account the process involved in developing the system, the following were concluded from the study:

1) The design and development of a mobile web-based student integrated information system was developed with the functional requirements;

2) The student integrated information system can now be accessed through internet with the use of any platform of mobile phones; and

3) The system was evaluated that showed the respondents strongly agreement with the system's acceptability in terms of functionality, reliability, efficiency, usability, maintainability and portability.

\section{RECOMMENDATIONS}

Based on the foregoing conclusions the following are recommended:

1) Provision of creation of schedule of teaching assignment of the faculty members automatically to extend the capability and functionality of the system;

2) Enrollment system, including assessment and payment of the students, to be added in the system as an additional feature of the system; and

3) Subject the system to actual use by all of the colleges of Manuel S. Enverga University Foundation in Lucena City, Philippines.

\section{REFERENCES}

[1] G. Steele, M. Leonard, C. Haberle, and W. Lipschultz, "Technology and academic advising," Academic Advising News, vol. 21, 2000.

[2] S. Murray and L. L. Blanc, "A decision support system for academic advising," presented at the 1995 ACM Symposium on Applied Computing, Nashville, TN, USA, February 26-28, 1995.

[3] J. B. Zimmerman. (1999). Mobile computing: Characteristics, business benefits, and the mobile framework. [Online]. Available: http://ac-support.europe.umuc.edu/ meinkej/inss690/zimmerman/IN SS\%20690\%20CC\%20\%Mobile\%20Computing.htm/

[4] R. Romando. (March 28, 2007). What is mobile computing. [Online]. Available:

http://ezinearticles.com/?What-is-Mobile-Computing?\&id=408148

[5] A. A. Ghamdi, S. A. Ghuribi, A. Fadel, and F. A. A. T. A. Ruhaili, "An Expert system for advising postgraduate students," International Journal for Computer Science and Information Technology, vol. 3, no. 3, 2012.

[6] T. Feghali, I. Zbib, and S. Hallal, "A web-based decision support tool for academic advising," Educational Technology \& Society, vol. 14, no. 1, pp. 82-94, 2011.
[7] O. Daramola, O. Emebo, and I. Afolabi, "Implementation of an intelligent course advisory expert system cased-based course advisory expert system," International Journal of Advanced Research in Artificial Intelligence, vol. 3, no. 5, 2014.

[8] A. A. Chandio, D. Zhu, and A. H. Sodhro. (2012). Integration of inter-connectivity of information system (i3) using web services. [Online]. Available: http://www.iaeng.org/publication/IMECS2012/IMECS2012_pp651-6 55.pdf

[9] S. P. Moe, "Design and evaluation of user-centric information system," Master's Thesis.

[10] M. N. Ismail. (2009). Development of WAP based students information system in campus environment. [Online]. Available: http://www.ijcte.org/ papers/043.pdf

[11] B. Xi, "A smart hill-climbing algorithm for application server configuration," presented at the WWW2004, New York, USA, May 17-22, 2004

[12] P. D. Stone, "Query delegation and hill climbing algorithms for DDFD join queries," US Army Research Laboratory and the UK Ministry of Defense, 2001.

[13] J. A. Freeman and D. M. Skapura, Neural Networks (Algorithms Applications and Programming Techniques), Addison Wesley Publishing Company, 2006, pp. 223-226.

[14] S. Russell and P. Norvig, Artificial Intelligence a Modern Approach, 2006.

[15] Amit. (2010, March 14). Hill Climbing: A simple optimization method [Web blog message]. [Online]. Available: http://echorand.me/2010/03/14/hill-climbing-a-simple-optimizationmethod/

[16] PHP. NET (2008). PHP hypertext processor. [Online]. Available: http://www.php.net

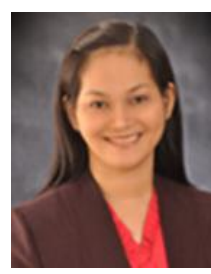

Maria Cecilia G. Cantos was born in Lumban, Laguna, Philippines, on December 5, 1981. Prof. Cantos earned her master degree of science in computer science at the AMA Computer College, Makati Campus, Philippines in 2007. Furthermore, Prof. Cantos finished her bachelor degree of science in computer science at AMA Computer College in Sta Cruz, Laguna Campus, Philippines in 2002

She has been teaching in the academe since 2002. She is currently working as an associate professor IV and the discipline research coordinator in the College of Computer Studies in Manuel S. Enverga University Foundation in Lucena City, Philippines. Her specializations are computer application using word, excel, powerpoint and access; computer organization with assembly language and hardware servicing; digital electronics circuit and design, and networking fundamentals. She is one of the researchers of the CHED HERRC research and development program II with the project title "Developing Pinoy-Designed Interactive Modules".

Over the years, Prof. Cantos has gathered IT certifications in Cisco Certified Network Associate (CCNA), Microsoft Certified Professional (MCP), Microsoft Office Specialist (MOS) for Office Word 2007, and Microsoft Technology Associate (MTA) for Windows OS Fundamentals and Network Fundamentals. 